\title{
Comparison, Contrast and Similarity in Yalaku
}

\author{
Alexandra Y. Aikhenvald \\ Language and Culture Research Centre, James Cook University
}

Yalaku, a Ndu language from the Middle Sepik region of the East Sepik Province of Papua New Guinea, has no dedicated comparative construction - just like an overwhelming majority of Papuan languages of New Guinea (de Vries 2015). After a brief outline of typological features of the language, we turn to the ways of expressing comparative meanings. The expression of similarity is the topic of $\$ 3$. The last section contains a summary.

\section{The Yalaku language}

Yalaku$^{1}$ is spoken by c. 300 people in the village of Yalaku located in a mountainous area off the Sepik River in the East Sepik Province of Papua New Guinea ${ }^{2}$ - see Map 1.

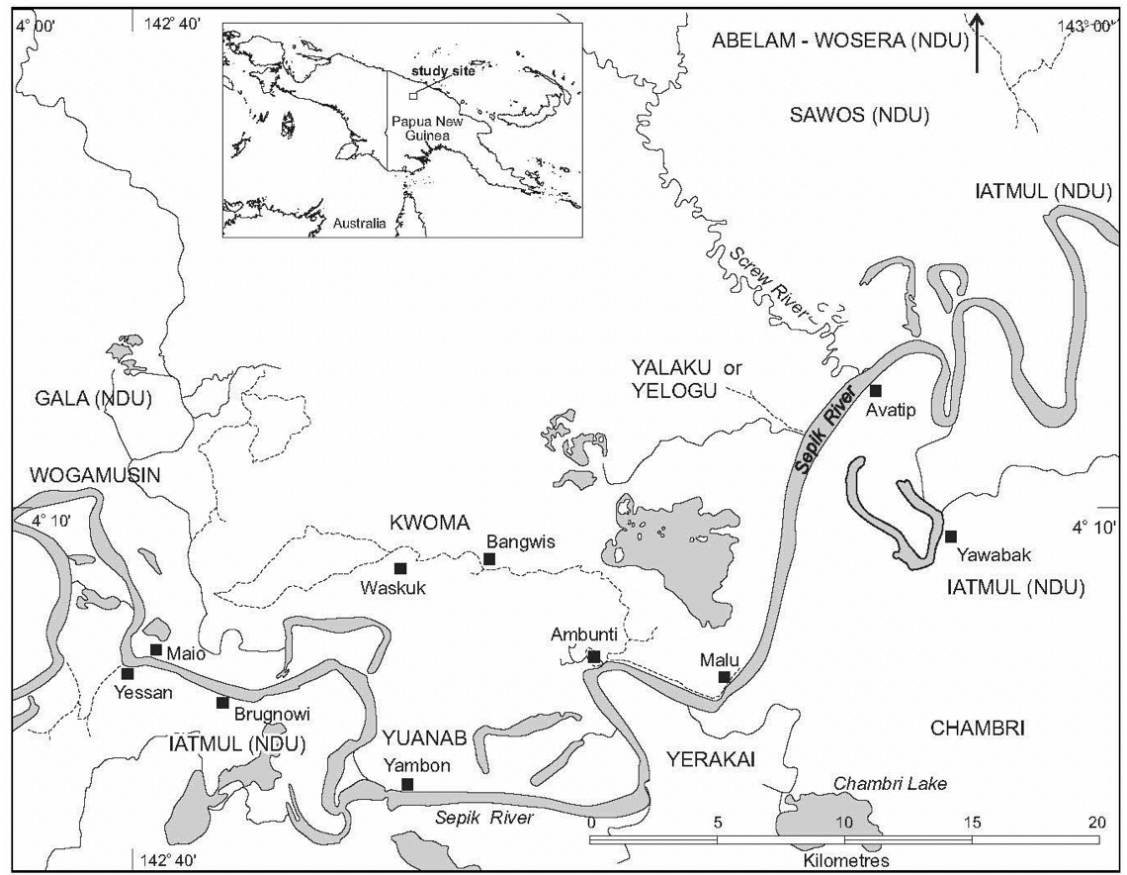

Map 1. The Yalaku language

${ }^{1}$ I am grateful to my Yalaku family, especially Joel Ukaia, Mark, David Kwaibori, and Solomon who taught me their remarkable language. I am indebted to R. M. W. Dixon for extensive comments and suggestions, and to Kasia Wojtylak for her insightful analysis of Murui, her comments and discussions. Thanks go to Brigitta Flick and Jolene Overall for proof-reading the paper.

${ }^{2}$ The original name of the language and the people is Yelahambura. The language was formerly called Yelogu (Bowden 1997; Laycock 1965). It is called Kaunga by the Kwoma (hence this alternative name cited in Bowden 1997). The language has never been previously described. A four-page outline of Yalaku grammar by Laycock (1965: 13943) is replete with mistakes and misinterpretations (details in Aikhenvald 2015a). This study is based on original fieldwork in the Yalaku village and the surrounds in 2013, 2014 and 2016. The corpus consists of ten hours of transcribed narratives in addition to fieldnotes based on participant-observation. Just as in all my work, grammatical elicitation using a contact language has been carefully avoided. 
Yalaku belongs to the Ndu language family, together with its closest relative Manambu, and also Iatmul and a few other languages (see Aikhenvald 2008: 591-4). Yalaku has twenty-two consonants and six vowels. All voiced stops and fricatives are prenasalized intervocalically; wordinitial $p, t$ and $k$ are voiced on a clitic boundary. The presence of consonant voicing on a clitic boundary is a major phonological process which distinguishes clitics from affixes (see Aikhenvald 2015a: 243-6). All clitics in Yalaku are 'special clitics': they can be cliticized (procliticized or encliticized) to their host or form an independent phonological word depending on speech register and syllable structure of the host. In addition, Yalaku displays the phenomenon of 'anticipatory cliticization', whereby a clitic can attach to the preceding word depending on its syllable length (details are in Aikhenvald 2015a: 245). Final vowel elision is a feature of normal to rapid speech register; for instance, the verbal declarative suffix - $k e$ can be pronounced as - $k$ (as in (30) in §3.2). There are no word-internal consonant clusters.

The language is nominative-accusative (a general feature of Ndu and neighbouring languages), synthetic and predominantly suffixing, with just two prefixes. Grammatical relations are expressed through cross-referencing on verbs and cases on nouns. Yalaku has eight clausal cases (zeromarked nominative, accusative-allative, dative, aversive, locative-instrumental, specific locative, future purpose, and comitative). Pronominal and definite objects can be marked with the object case (see Aikhenvald 2015a, for a discussion of two subsystems of differential object marking in the language). A zero-marked form is used for subjects, copula complements, and the second argument of the verbs of change of state including 'turning into something'. The locative case can be omitted if the locational meaning is clear from the context or the noun has a locational or temporal meaning.

Open word classes are nouns, verbs, and adjectives; closed classes include personal pronouns, interrogatives, demonstratives (which distinguish five degrees of distance), quantifiers, time words and locationals. Three numbers (singular, dual and plural) and two genders (masculine and feminine, in the singular only) are expressed covertly (through agreement markers on demonstratives, verbs and in an archaic possessive construction (30) rather than on nouns themselves). Number (singular, plural and dual) is overtly marked only on kinship nouns. Adjectives have a few specific affixes, among them the augmentative (§2.3). Verbs cross-reference person, gender and number of the subject $(\mathrm{A} / \mathrm{S})$. Further verbal categories include mood (declarative, imperative, interrogative), tense (present/non-future, completed/past, future), aspect (habitual, completive), modality (desiderative, intentional, frustrative, and apprehensive), and complex negation marking. Types of main clauses include verbal, copular and non-verbal clauses. Non-main clauses cover switch reference sensitive clauses (same subject and different subject ones), co-temporaneous clauses, relative clauses, and purposive clauses. Within switch reference sensitive clauses, the verb in a dependent clause shows whether its subject is the same as, or different from, that of the following clause. Same-subject clauses do not take subject crossreferencing, while different subject clauses do. This feature - typical of Ndu languages (cf. Aikhenvald 2008, 2015a) - helps establish a robust category of subject (A/S).

Relative clauses are marked with the verbal suffix $-d(e)$. An additional verbal form (marked with a special set of verbal cross-referencing markers and the suffix $-k o$ ) expresses activity at the moment of speech. This form can be used as a complementation strategy and in dependent clauses expressing activity co-temporaneous with that of the main clause.

In addition, just like in many other languages, full reduplication can be used to differentiate word classes. With nouns, reduplication has a distributive meaning; with verbs it has a repetitive meaning; and with adjectives it has an intensifying meaning. There are no productive word-class changing derivations. A member of any word class can occupy the intransitive predicate slot (with limited possibilities for non-verbs). Similarly to Manambu and other related languages, Yalaku 
has a productive system of serial verbs (which form one grammatical and one phonological word); these often involve motion verbs.

Constituent order is predominantly verb final $(\mathrm{AO}($ Oblique $) \mathrm{V} / \mathrm{S}($ Oblique $) \mathrm{V})$, but not strictly so. A constituent in contrastive focus or an afterthought can be postposed to the predicate.

\section{How to express comparison in Yalaku}

Yalaku has no dedicated comparative construction for what is known as "comparison of inequality". Two comparative "strategies" (in the sense of Dixon 2012: 341-61) can be used to compare people and objects (but not actions or abstract entities). Each of the two strategies involves an implicit contrast. We start with a strategy involving directional verbs.

\subsection{Directional verbs, and the expression of comparison}

One way of expressing such contrast is by using directional verbs wor-(e)- 'go up' (for comparison of superiority), and tada- 'go down' and kaya- 'go down slope' for comparison of inferiority. The directional verbs are used in the meaning of a "parameter marker" (which corresponds to the index of comparison: see Dixon 2012: 341-61). ${ }^{3}$

Comparing myself with a friend who is much taller than me, I was instructed to say (clauses are in square brackets): ${ }^{4}$

$\begin{array}{llll}{[\text { wuni }} & \text { tada-wuni }] & {[\mathrm{le}=\text { wore-i-te }]} & {[\mathrm{le}=\mathrm{i}-\mathrm{ke}]} \\ \mathrm{I} & \text { go.down-1SG } & \text { 3FEM.SG=go.up-go-SS } & \text { 3FEM.SG=go-DECL }\end{array}$

[semi-semi takwa-1]

tall/long-tall/long woman-3FEM.SG

'I am shorter than her (lit. I go down, she having gone up she goes), she is a very tall woman'

A child was compared with his father in (2), followed by a statement about the father being tall.

\footnotetext{
${ }^{3} \mathrm{~A}$ note on the glossing principles adopted here and in my other publications on Ndu languages. Firstly, independent pronouns, such as wuni ' $\mathrm{I}$ ' in (1), are glossed using corresponding English independent pronouns. Bound pronouns, including clitics (set off with the equal sign $=$ ) and suffixes (set off with a dash), are glossed using grammatical labels such as $3 \mathrm{fem} . \mathrm{sg}$ in (1). Secondly, many Yalaku words are polysemous, that is, have more than one meaning. To make the glossing as reader-friendly as possible, I gloss each occurrence of a polysemous word with the meaning it has in that instance of use. So, the adjective mafui which can mean 'big' or 'fat' is glossed as 'big' in (8) (where it means 'big') and as 'fat' in (10) where it means 'fat', rather than 'big'. See Aikhenvald (2015b: 17) on user-friendliness in glossing and in grammar-writing.

${ }^{4}$ ACC - accusative, ALL - allative, ANAPH - anaphoric, AUG - augmentative, COMIT - comitative, COMPL completive, COMPL.SS - completive same subject clause, COTEMP - co-temporaneous clause marker, DECL declarative, DEM.DIST - distal demonstrative, DEM.FURTHER.DIST - demonstrative denoting a distance further than mid-distance, DEM.MID.DIST - demonstrative denoting mid-distance, DEM.PROX - proximal demonstrative, DS - different subject, DU - dual, FEM.SG - feminine singular, FOC - focus, FUT - future, GEN - genitive, IMPV imperative, masc.sg - masculine singular, NEG - negation, NEG.EXIST - existential negator, NEG.NOM - nominal negator, NON.NOM - non-nominative form of a pronoun, PL - plural, PRED - predicate marker, PURP - purposive, RED - reduplication, REL - relative clause marker, SG - singular, SS - same subject
} 
(2) [padi tada-d], [tu wore-d], [semi-d] child go.down-3MASC.SG man go.up-3MASC.SG tall/long-3MASC.SG 'The child is smaller than the father, (the father) is tall' (lit. Child goes down, man goes up, (he) is tall)

Either of the first two clauses can be omitted, if the idea of a comparison is clear from the context. On another occasion, a speaker commented on a difference in size between him and another person. Example (3) contains an implicit comparison of inferiority.

\section{(3) wuni kaya-wuni \\ I go.down.slope-1sG \\ 'I am smaller (than the other person)' (lit. I go down)}

A statement of a comparison of inferiority can be accompanied by a size adjective. In (4), this is a copula complement in the first clause.
(4)
[foi $=$ de-t $], \quad$ [tada-d] short=3MASC.SG-be go.down-3MASC.SG
'He is short, he is shorter (than the other child)' (lit. He goes down)

Example (5) is an instance of comparison of superiority. The first clause contains a size adjective; this is a way of clarifying the parameter of comparison. The standard is implicit; it is always recoverable from the context of conversation.
[semi=de-te]
[wore-i de-te] tall/long=3MASC.SG-stay go.up-go 3MASC.SG-be
'He is tall, he goes up (in height)' (lit. Go up go he is)

Alternatively, the parameter may be stated in a separate clause, as in (6). 'Age (lit. her years)' is the subject of the first (dependent) clause. It is understood as a parameter within the context.

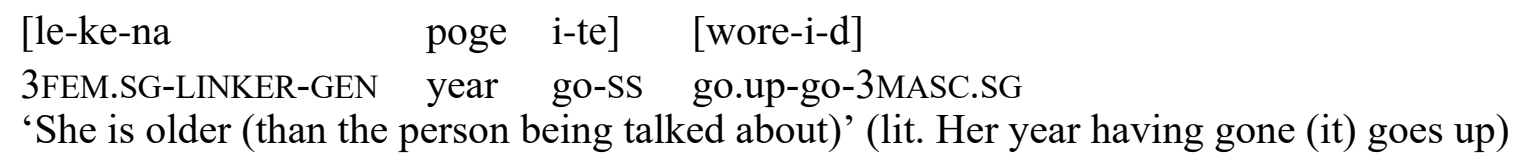

Alternatively, a parameter can be optionally added, as in (7). The parameter ('my year(s)') cannot receive any case marking. The construction is reminiscent of a monoclausal comparative construction involving location in space (somewhat similar to comparative constructions in Murui which involve a locational term, as described by Wojtylak, this volume). Its status in terms of grammatical relations is ambiguous, and the issue of its status as an obligatory argument or an optional oblique remains open. The parameter cannot be referred to with an anaphoric demonstrative, it cannot be questioned, or coordinated with any other constituent, and is thus different from other arguments and obliques. 


$$
\begin{array}{llll}
\text { [te } & \text { wuna-na } & \text { poge } & \text { kaya-d] } \\
\text { he } & \text { 1SG.NON.NOM-GEN } & \text { year } & \text { go.down.slope-3MASC.SG }
\end{array}
$$

'He is younger than me' (lit. He goes down slope (with respect to) my year(s))

The two verbs of downwards motion - tada- 'go down' and kaya- 'go down slope' - are used interchangeably in the comparative context. For each of (1)-(4) and (7), either was judged acceptable (note that such examples are rare and restricted to conversations). When used to imply comparison, the verbs meaning 'go up' and 'go down' in their comparative meaning cannot be serialized or accompanied with directionals ('uphill', 'downhill', 'inside', 'outside'), in contrast to their use as verbs of motion.

The verbs wore- 'go up' and tada- 'go down' can also be used to indicate increase or decrease in a particular quality, as in (8) and (9). The comitative case marker on the verbal root indicates the gradual character of the process (see Aikhenvald 2011, for a typological and areal perspective for the case morphology on verbs in Papuan languages, and Aikhenvald 2009 on case markers as clause linkers in Ndu languages).

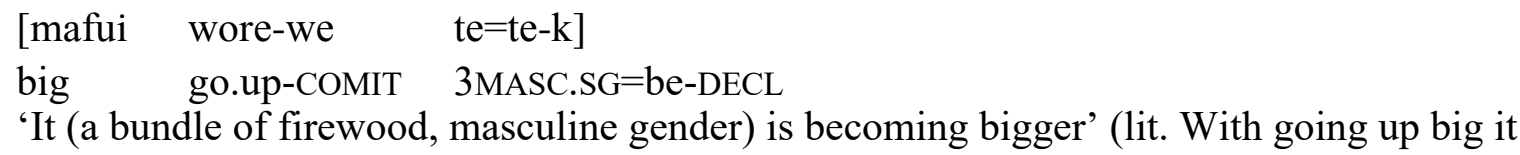
is)

(9) [wosek tada-we te $=$ te-k] small go.down-COMIT 3MASC.SG=be-DECL

'It (food supply, masculine gender) is becoming smaller' (lit. With going down small it is)

What we have seen so far is the deployment of verbs of motion and direction - 'go up' and 'go down' - as comparative strategies expressing comparison of superiority and inferiority respectively. Such uses do not seem to be intuitively implausible. However, cross-linguistically they appear to be uncommon.

The verb 'go up' as the indicator of comparison of superiority is reminiscent of the expression of comparative or superlative with a verb meaning 'surpass' or 'exceed' (type B in Dixon 2012: 354-5). Using the notions of direction and space in comparative strategies is not unlike the comparison of superiority in Murui, which involves spatial notions of distance ('ahead'), position in space ('high') and interiority ('outside'). The comparison of inferiority in Murui relates to interiority ('inside') and position in space ('low'). Verbal modifiers meaning 'up' and 'down' are deployed as markers of a comparison of superiority and inferiority respectively in Boumaa Fijian (Dixon 1988: 88). These appear to be the closest analogies to what we have just seen in Yalaku. However, having a purely directional verb 'go up' used to mark comparison of superiority and its counterparts meaning 'go down' as a marker of a comparative of inferiority (predominantly in biclausal sentences) appears to be cross-linguistically uncommon. There is no full equivalent to these in any of the related or neighbouring languages described so far.

Comparative uses of directional verbs in Yalaku occur only in informal conversations, and are avoided in careful speech and planned narratives. We now turn to a more common comparative strategy which permeates the language. 


\subsection{Contrasting properties: a further comparative strategy in Yalaku}

Similar to numerous Papuan languages, including some of the Ndu languages, Yalaku employs a contrastive strategy to express comparison (see Dixon 2012: 359, and de Vries 2015). Two verbless clauses are juxtaposed. Examples (10) and (11) show that the order of the terms of dimension is determined by speaker's choice. Example (10) comes from a conversation, and (11) comes from a traditional story.

$\begin{array}{llll}\text { [wuni } & \text { afareka } & {\left[\begin{array}{ll}\text { le } & \text { mafui] }\end{array}\right.} \\ \text { I } & \text { thin/skinny } & \text { she } & \text { big/fat }\end{array}$

'She is fatter than me' (lit. I thin, she fat)

(11) [noke semi] [noke foi] one tall/long one short 'One (was) taller than the other' (lit. One (wife of a man from a story) (was) tall, one short)

A comparative reading of this strategy presupposes a logical connection between two dimensions (or an "implicature", as pointed out by de Vries 2015) - that is, if one person is tall and the other one is short, then the two can be understood as being compared. The comparative reading is optional. Whether or not comparison is implied is usually clear from the context. When I asked my teachers of Yalaku about the fate of the Apukili (an almost extinct group who were defeated by the Kwoma and the Yalaku about two generations ago), I was told that their leader, Pakiyey, had been killed in battle and all his household - except for his two young wives - exterminated. The two women - married off to a respected Yalaku elder - were very different. They were contrasted as follows - see (12). The contrast did not have any comparative overtone; (12) was a simple statement of a fact.

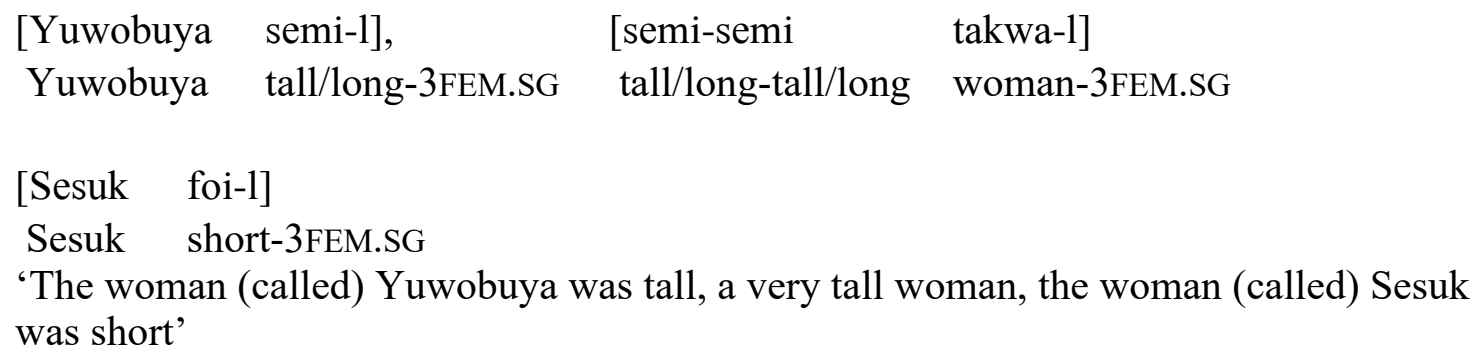

[Sesuk foi-1]

Sesuk short-3FEM.SG

'The woman (called) Yuwobuya was tall, a very tall woman, the woman (called) Sesuk was short'

This brings us to a prominent feature of Yalaku conversations and narratives - contrasting participants in terms of their properties. This can be done by using antonyms (as in (12)), or by negating one of the adjectives. In (13), a really big woman appears to a man; the speaker stresses that she is huge, big and not small (clauses 2 and 3). The fact that she is 'big' is repeated (using the adjective $m a f u i$ 'big') in the fourth clause. 
(13)
[takwa nok yafa-sake-ñene hobu-t ya-la-ka
woman one huge-AUG-baby carry.on.shoulder-SS come-3FEM.SG-DS

$\begin{array}{lll}\text { ku-yaku-taka-k] } & {[\text { Yafa-sake }} & \text { takwa-l] } \\ \text { water-wash-put-PURP.SS } & \text { huge-AUG } & \text { woman-3FEM.SG }\end{array}$

[wosek-luwa-k] [mafui-1]

small-NEG.NOM-DECL big-3FEM.SG

'(A man saw) a woman come and carry a big baby to wash, she was a huge woman, she wasn't small, she was big'

Headlessly used adjectives 'big' and 'small' are contrasted in (14). This is a way of emphasizing the fact that they had got a small quantity of firewood.

$\begin{array}{lllll}\text { [pre } & \text { hebo-mafui } & \text { hara-t] } & \text { [woseke=ber } & \text { hara-k] } \\ 3 \text { DU } & \text { NEG-big } & \text { get-SS } & \text { small=3DU } & \text { get-DECL }\end{array}$

'The two of them didn't get a big (quantity of firewood), they got a small (quantity)'

(lit. Them two having got not big (quantity), they got small (quantity))

A spirit gave a man two wives - two very different women, contrasted in their properties in (15): one was black and the other one was white, one was good-looking, the other one was ugly, or badlooking. Note that the subject cross-referencing is omitted in a sequence of coordinated main clauses as it is clear from the context.

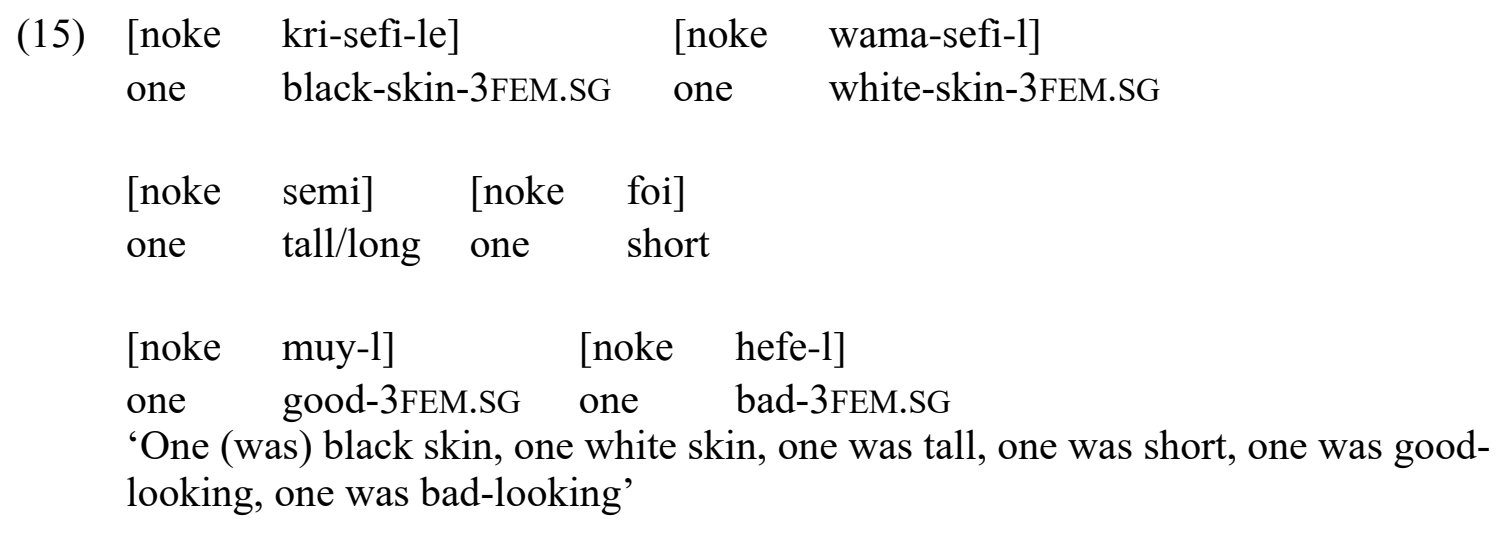

All the speakers of Yalaku are bilingual in Tok Pisin, the creole lingua franca of Papua New Guinea. Contrasting adjectives in Tok Pisin narratives and conversations are used in much the same way as in Yalaku. For instance, talking about a really big house, a number of speakers said em i bikpela, em $i$ no liklik (he/she/it PRED big, he/she/it PRED NEG small) 'it is big, it is not small'. Talking about a small boy, a speaker remarked em i liklik, em i no bikpela (he/she/it PRED small, he/she/it PRED NEG big) 'he is small, he is not big'.

None of the contrastive constructions described in this section has a dedicated comparative meaning (though each can be understood that way). They can be considered an expressive device for emphasizing a property, deployed by story tellers. 


\subsection{How to express a superlative in Yalaku}

Just like in many Papuan languages, Yalaku has no dedicated superlative. Several strategies can be interpreted as having superlative overtones. The augmentative suffix -sak used with two size adjectives mafui 'big' and yafa 'huge' can be understood as a superlative. The woman discussed in (16) was the biggest of all on a photograph. This example comes from a conversation. Her large size was further emphasized by the adjective 'huge' with an augmentative in the second clause.

\section{[mafui-sake-1], [yafa-sake-1] \\ big-AUG-3FEM.SG huge-AUG-3FEM.SG}

'She is very big, she is very huge' (in context: the biggest of all)

In contrast, in (13) the augmentative yafa-sake (huge-AUG) 'huge' cannot be understood as a superlative, since there is no comparison implied: the woman discussed there is the only woman in that story (and so is the 'huge' baby).

The adjective yafa 'huge' has the same form as yafa 'father', and in all likelihood is derived from it. Yafa is used as a modifier with the meaning 'big', usually accompanied by the adjective 'big', e.g. mafui yafa tu (big father man) 'a huge man', or nubu yafa tu (truly/land-based father man) 'a huge man, an important man (Tok Pisin bikpela man, leader)'. The word 'father' is used as an augmentative modifier in related languages, including Manambu (see Aikhenvald 2008: 120).

Compounds containing the adjective muy 'real, good', ${ }_{5}$ e.g. muy-nar (real/good-nice) 'very good', mиy-wul (real/good-multiply/overflow) 'fat, healthy', can be interpreted as superlatives given the right context, and so can a reduplicated adjective with an intensive meaning, e.g. semisemi 'very tall' in (1) (\$2.1) and (12). In each case, a superlative reading is contextual.

We now turn to the comparison of equality, and the ways of expressing similarity.

\section{Similarity and equality in Yalaku}

\subsection{Expressing similarity}

Talking about similarity and also equality is a pervasive feature of Yalaku narratives and conversations. The suffix -meki (with a variant -moeki) 'like, similar, equal, the same' can be used with a copula complement, as in (17), where the copula complement of the verb 'be' is meda 'cassowary', and also in the last clause in (25). Constituents within the scope of -meki are in braces.
(17) $\quad[$ une
meda-meki $\quad$ le=te-k]
DEM.DIST.ANAPH.MASC.SG cassowary-LIKE 3FEM.SG=be-DECL
'She was like that cassowary (as she put on a cassowary skin)'

The suffix 'like' can also be used with an object as in (18), and location, as in (19). This suffix goes onto the last constituent of a possessive noun phrase, as in (19) (just like case markers in Yalaku: see Aikhenvald 2015a). It can occur on a prehead modifier — see example (22).

\footnotetext{
${ }^{5}$ Value terms in Ndu languages are polysemous (cf. Aikhenvald 2008: 568-70) The adjective muy 'real' in Yalaku means 'real, good, appropriate' and covers the meanings of its Manambu cognate muy 'real, true' and a non-cognate Manambu adjective vyakat 'good, appropriate for its purpose'.
} 
(18)

$[\{$ safa-meki $\}=$ de $\quad$ so-k $]$

mask-LIKE=3MASC.SG wear-DECL

'He was wearing (something) which was reminiscent of a mask (lit. like a mask)'

[patsamo te =te-k \{Joel te-ke-na kai-meki $\}$ ]

close 3MASC.SG=be-DECL Joel 3MASC.SG-LINKER-GEN house-LIKE

'It was close, like Joel's house'

A constituent marked with -meki can express manner on a noun, as in (20).

[ubre ñane $\quad\{k u-m e k i\}=$ bere fofore-ke]

DEM.DIST.DU child water-LIKE=2DU rise.roaring-DECL

'Those two children grew rapidly' (lit. Those two children rose roaring like water)

The suffix -meki can occur on an anaphoric demonstrative, as in (21).
[\{ane-meki\}
wore-te] [ene
fetegutsi
DEM.PROX.MASC.SG-LIKE
go.up-SS
DEM.MID.DIST.MASC.SG
door
safwi-k hor-te]
open-PURP.SS be.about.to/get-SS
'Having gone up like this (showing), being about to open that door (he was captured by the spirit woman)'

In (22), -meki occurs on a demonstrative adverb used as a modifier.
[ñana-we
\{ukwa-meki
poko $\}$ te $=$ te-k]
that way-LIKE thing $3 \mathrm{MASC} . \mathrm{SG}=\mathrm{be}-\mathrm{DECL}$
'We have things of that sort' (lit. With us are things like those (which are) that way)

The meaning of -meki is similarity and resemblance in its many overtones (see, for instance, Fortescue 2010: 198-19, on a plethora of overtones of similarity markers). It would be an oversimplification to limit -meki (or any other similarity marker) to just 'comparison'.

The suffix can occur on two types of clauses. It is used with a relative clause in (23). Here, the head of the relative clause is omitted, and the common argument is the subject. The previous 'state' of a cassowary is shown to be 'like' what she was at present.

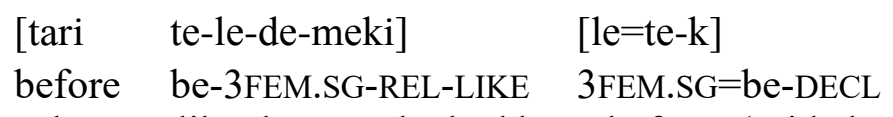

'She was like the one she had been before' (said about cassowary who had become a woman and then had turned back into a cassowary) (lit. Before being like she is)

A co-temporaneous clause marked with -ko can occur with -meki if activities or states resemble each other (with implicit comparison of similarity). In (24), from an advice about how to suck a lozenge, the clause marked with -meki 'like' refers to manner of action - that is, 'consuming' a 
lozenge like one would consume a lolly (similar to other Ndu languages, Yalaku has just one verb covering 'eating', 'drinking', 'sucking' and 'smoking' which is covered by 'consume' in the translation).
[loli ha-men-ko-meki]
[puri=ha]
lolly consume-2MASC.SG-COTEMP-LIKE FUT=consume.IMPV
'Consume it (the lozenge) later like you consume a lolly'

In (25), a clause marked with -meki 'like' occupies the copula complement slot:

$\begin{array}{lllll}\text { [ñana-de-na } & \text { yafa-yafa } & \text { kolmadeka } & \text { tse } & \text { hebo } \\ \text { we.PL.NON.NOM-FOC-GEN } & \text { father-father } & \text { ancestor } & \text { they } & \text { NEG }\end{array}$

$\begin{array}{llll}{[\text { ñani }} & \text { te-bo-ko-meki }] & \text { tse }=\text { te-ke }], & {[\text { hekets }]} \\ \text { we.PL } & \text { be-1PL-COTEMP-LIKE } & \text { 3PL=be-DECL } & \text { NEG.EXIST }\end{array}$

[tsoki holereka-meki tse=te-k]

they + too gigantic.spirit-LIKE $3 \mathrm{PL}=$ be-DECL

'Our forefathers, ancestors, they were not like we are, no, they too were similar to gigantic spirits called holereka'

In an appropriate context, a clause marked with -meki can be interpreted as expressing pretence (or a 'simulative' 'as if') (in agreement with Fortescue 2010: 119). In (26), a spirit woman pretended she was leaving the house (first clause), but instead killed the real woman, Heji (third clause). The suffix -meki 'like' appears on a headless relative clause (first clause):
[vala-le-de-meki]
[Heji-re
vya-rugwa-t]
[yarugwa-t]
go.out-3FEM.SG-REL-LIKE
Heji-ACC
hit-turn-SS
kill-SS
[væki-rugwa-taka-tat $] \quad[\mathrm{le}=$ sotsi-k kai-r $]$
step-turn-put-COMPL.SS 3FEM.SG=go.out-DECL house-ALL
'As she pretended to be going out (lit. the one who pretended to be going out), having turned and hit Heji, having killed (her), having turned her upside down by stepping on her, she went home'

Example (27) was a comment about people who behaved as if they were staying in mourning (but in fact were not):
[kaba re-do-ko-meki $] \quad[$ tse $=$ te-k $]$
spirit.state sit-3PL-COTEMP-LIKE 3PL $=$ stay-DECL
'They are as if they were in mourning' (lit. Like they stay in a spirit state)

The suffix -meki 'like' cannot occur on subjects, and is not compatible with any of the case markers on nouns. This feature appears to be shared with the unrelated Kwoma, a language with which Yalaku has been in contact for a long time (Bowden 1997: 21; Kooyers 1974: 33-4). In contrast, 
the suffix -pek 'like, similar to' in Manambu, Yalaku's closest relative, can occur with case markers (Aikhenvald 2008: 191). A further difference between the similative -pek in Manambu and -meki in Yalaku lies in the fact that -pek marks similarity in manner clauses which have all the features of main clauses while -meki can only occur on relative clauses and on co-temporaneous clauses (examples (23)-(24)).

The status of the suffix -meki is debatable. On the one hand, it appears to share features with oblique case-markers. A major argument in favour of this analysis is the fact that it attaches to a non-nominative form of a personal pronoun, just like non-nominative case markers in general, e.g. $\tilde{n} a n i$ 'we (pl) (nominative case)', ñana-ka (1PL.NON.NOM-DATIVE) 'to us (pl)', ñana-meki (1PL.NON.NOM-like) 'like us (pl)'. However, the similative can occur on headless relative clauses and co-temporaneous clauses, unlike any of the case markers, and thus cannot be considered a member of the same system. ${ }^{6}$

\subsection{Expressing equality}

The only means of expressing equality in Yalaku is by using a lexical item. The reduplicated adjective kara-kara 'equal' is typically used as a copula complement of the verb te- 'be' to express equality between people or qualities. Example (28) comes from a narrative about what happened with the Yalaku people during the Second World War:

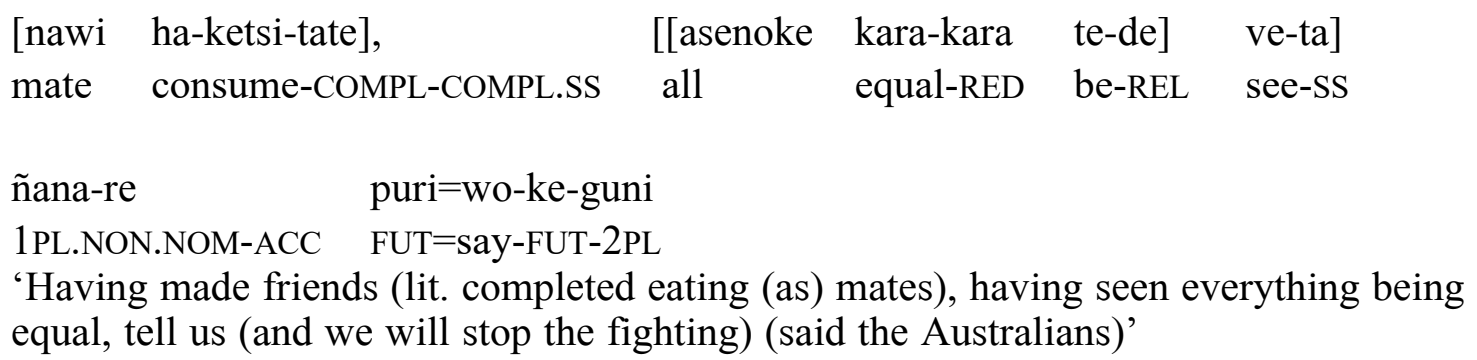

The form karakara can have the meaning of 'be enough, be all over', as in (29).

\begin{tabular}{|c|c|c|c|}
\hline endekate & $\begin{array}{l}\text { ñiki } \\
\text { blood }\end{array}$ & $\begin{array}{l}\text { i-i-te] } \\
\text { go-go-SS }\end{array}$ & $\begin{array}{l}\text { e-de-ka], } \\
\text { h-3MASC.SG-DS }\end{array}$ \\
\hline . & & & {$[1 \mathrm{e}=$} \\
\hline loug & e-z & SC.SG-DS & $3 \mathrm{FEM} . \mathrm{SG}=\mathrm{d}$ \\
\hline
\end{tabular}

'So as the blood flowed, after it (blood) finished, after it was all over (enough), she died'

The unreduplicated form kara means 'enough, finished', in archaic stories told by older and traditional speakers. Its typical context is in the endings of stories, as in (30):

\footnotetext{
${ }^{6} \mathrm{~A}$ number of other cases (including dative and aversive 'for fear of') can occur on verbal roots to form dependent clauses (Aikhenvald 2015a); no cases can occur on the predicate of non-main clauses of other types. Etymologically, -meki is cognate to the generic verb megi 'do whatever, act in whatever manner, act like (previously mentioned action)' in Manambu (see Aikhenvald 2008: 571-2).
} 

wuna-ke-le
hudi kara
ole-k
1SG.NON.NOM-LINKER-FEM.SG talk enough
DEM.FURTHER.DIST-DECL
'The story of mine is enough, this is it'

The polysemy 'enough, be equal' described for kara is reminiscent of Manambu: the Manambu stative verb rep 'sufficient, enough' means 'be equal' if reduplicated, e.g. repe-rep te-na-bran (equal be-ACTION.FOCUS-1DU) 'we two are equal (e.g. in size or age)') (cf. Aikhenvald 2008: 90, $671)$.

\section{What can we conclude?}

Yalaku has little in the way of comparative constructions. Biclausal or monoclausal constructions involving directional motion verbs 'go up' and 'go down' can express comparison of superiority or inferiority (\$2.1). However, when used as comparative strategies, the verbs 'go up' and 'go down' have somewhat different properties than in their typical uses as motion verbs, in terms of occurring in serial verb constructions. This comparative strategy — limited to conversations - is somewhat unusual cross-linguistically. Contrasting properties - without necessarily implying comparison - is a feature of Yalaku narratives (\$2.2). Biclausal constructions involving contrast can be interpreted as implying comparison, depending on the context. This is a typical comparative strategy, widespread across Papuan languages. The similative suffix -meki 'like' has a plethora of meanings to do with resemblance and pretense, and can be used to compare participants and activities. Given the right context, -meki can be interpreted as marking 'comparison of similarity' (as, for instance, in (17)).

Not only does Yalaku lack a dedicated comparative, or superlative. There are no lexemes to do with winning, exceeding someone and competition in general. This is in contrast to the closely related Manambu which has a comparative construction (see Aikhenvald 2008: 190) and two verbs with comparative meanings: kakel- 'compete' and $y i$ - 'go, exceed'. The verb $(y) i$ - 'go' in Yalaku does not have the meaning of 'exceed', in contrast to its cognate in Manambu. In narratives and conversations about beating someone in a battle, one just uses the various verbs for 'kill', 'beat' and 'overturn'. The lack of focus on competition and 'winning' was brought home to me by one of the speaker's comment on how the Manambu people are fixed on competing with everyone and exceeding others, and the Yalaku people are not. When talking about this, he used the Tok Pisin verb winim 'surpass, get ahead of someone' — there was no lexical or other means available in Yalaku.

There may be a societal explanation for this. As Dixon (2008: 814) put it, "small tribes with an egalitarian social system and item-for-item trade do not generally indulge in competition; they often lack words for 'compete', 'win', 'lose' and 'beat' (as in a game). Such concepts are tied in with comparison [...]. Groups of this type have little use for the idea of "more than' or 'less than". Along similar lines, "in the traditional culture of Dyirbal speakers, from North Queensland, and of the Jarawara, from southern Amazonia [...], there was no factor of competitiveness. The vocabularies include no words which could render 'compete', 'win', 'lose', 'victory', or 'victor'" (Dixon 2016: 93).

Dixon (2008: 814) continues: "There does, however, appear to be more of a tendency for such small societies, which lack a comparative construction, to have some linguistic device for saying 'be the same as, be equal to'." Yalaku, spoken in a small community with no pronounced social hierarchies, adds to this a frequently used construction involving similarity and likeness. 


\section{References}

Aikhenvald, Alexandra Y. 2008. The Manambu language of East Sepik, Papua New Guinea. Oxford: Oxford University Press.

Aikhenvald, Alexandra Y. 2009. 'Semantics of clause linking in Manambu'. Semantics of clause linking: a cross-linguistic typology, ed. by R. M. W. Dixon and Alexandra Y. Aikhenvald, 118-144. Oxford: Oxford University Press.

Aikhenvald, Alexandra Y. 2011. 'Versatile cases'. Language at large, ed. by Alexandra Y. Aikhenvald and R. M. W. Dixon, 3-43. Leiden: Brill.

Aikhenvald, Alexandra Y. 2015a. 'Differential case in Yalaku'. Oceanic Linguistics 54.240-269.

Aikhenvald, Alexandra Y. 2015b. The art of grammar. A practical guide. Oxford: Oxford University Press.

Bowden, Ross. 1997. A dictionary of Kwoma, a Papuan language of North-east New Guinea. Canberra: Pacific Linguistics.

Dixon, R. M. W. 1988. A grammar of Boumaa Fijian. Chicago: University of Chicago Press.

Dixon, R. M. W. 2008. 'Comparative constructions. A cross-linguistic typology'. Studies in Language 32.787-817.

Dixon, R. M. W. 2012. Basic Linguistic Theory. Volume 3. Further grammatical topics. Oxford: Oxford University Press.

Dixon, R. M. W. 2016. Are some languages better than others? Oxford: Oxford University Press.

Fortescue, Michael. 2010. 'Similitude: A conceptual category'. Acta Linguistica Hafniensia 42/2. 117-142.

Kooyers, Orneal. 1974. 'Washkuk grammar sketch'. Workpapers in Papua New Guinea Languages 6.5-74.

Laycock, D. C. 1965. The Ndu language family (Sepik District, New Guinea). Canberra: Linguistic Circle of Canberra Publications.

de Vries, Lourens. 2015. 'Comparative and superlative constructions in Papuan languages'. Paper presented at the Special Workshop Comparative and superlative constructions: typology and diachrony. Amsterdam, Vrije Universiteit, 16-17 June 2015. 